\title{
How Dose Flexible Cis-Octahydropentalene Carbonic Backbone, Help Populate A Single Bioactive Conformer in Chondrosterin J
}

\author{
Sahar Sakhaee ${ }^{1}$, Saghar Sakhaee ${ }^{2}$, Mohammad Hossein Sakhaee ${ }^{3}$, Akbar Mobaraki ${ }^{4}$, Ahmad $^{2}$ \\ Takallou ${ }^{5}$, Nader Sakhaee ${ }^{6 *}$ \\ ${ }^{1}$ Islamic Azad University, Mashhad Branch
}

${ }^{2}$ Medical University of Shahrood, Shahrood, Iran

${ }^{3}$ Mashhad University of Medical Sciences, Mashhad, Iran

${ }^{4}$ Department of Chemistry, Tarbiat Modarres University, P.O. Box. 14115-175, Tehran, Iran

${ }^{5}$ Department of Chemistry, Kharazmi University, Tehran, Iran

${ }^{6 *}$ Department of Mathematics and Natural Sciences, Harris-Stowe State University \& Department of Chemistry, Southern Illinois University, USA

*Corresponding author: Nader Sakhaee, Department of Mathematics and Natural Sciences, Harris-Stowe State University, St. Louis, MO, 63108, USA \& Department of Chemistry, Southern Illinois University Edwardsville, Edwardsville, IL 62025, USA

\section{ARTICLE INFO}

Received: 幽 October 06, 2019

Published: 幽 October 18, 2019

Citation: Sahar Sakhaee, Saghar Sakhaee, Mohammad Hossein Sakhaee, Akbar Mobaraki, Ahmad Takallou, Nader Sakhaee. How Dose Flexible Cis-Octahydropentalene Carbonic Backbone, Help Populate A Single Bioactive Conformer in Chondrosterin J. Biomed J Sci \& Tech Res 22(1)-2019. BJSTR. MS.ID.003708.

\section{ABSTRACT}

Cis-Octahydropentalenes are cyclic conformationally mobile carbonic skeletons occurring in a number of natural products. A complete conformational analysis of cisOctahydropentalenes are done in this work, using $\omega b 97 x d / 6-311+G(d)$ level of theory. Although for cyclopentane a conformational landscape can easily be plotted based on puckering and phase, such models for fused ring systems are a little complicated to build. Here a conformational landscape based on puckering of the envelope ring coordinates was suggested for cis-Octahydropentalene. The model was then tested to analyze the stable conformer in, Chondrosterin, a marine natural product. Chondrosterin seems to populate its bioactive form in a dynamic conformer, which is located at the very dead end of a rapid pseudorotational coordinate.

Keywords: Bioactive Conformers; Cis-Octahydropentalene; Conformational Dynamics; Pseudorotation; Partial Mobility

\section{Short Communication}

Bio chemists have been quite successful in proving that folding patterns in proteins is evolved upon natures ability to populate certain bioactive folded conformers. And though impossible it may seem to select among a myriad of folding patterns nature has used up enormous geologic time to its benefit to accomplish this. The first pseudo rotational model for cyclopentane was introduced by Lipnick et al. [1]. They suggested a wheel model of a of up to 20 conformers, put in a wheel setting [2,3] to illustrate cyclopentane conformational mobility. Further attempts [4-11] to classify these conformers mostly proved unsuccessful [12-14]. The concept of a spherical conformational landscape was introduced back (Figure 1) in 2016, to cyclopentane and some of its derivatives which helped fully explain their fluxional nature. A basic spherical conformational landscape was also presented for cis-octahydropentalene. Here it's been tried to analyze the conformational preferences of Cis-Octahydropentalene in a way to justify the conformational preferences of natural products containing this fascinating molecule. Our results with Chondrosterin and initial results with other natural products are rather a strong back up for the grand theory that nature exploits special features in certain cyclic carbonic scaffolds to achieve desired boioactivity. 


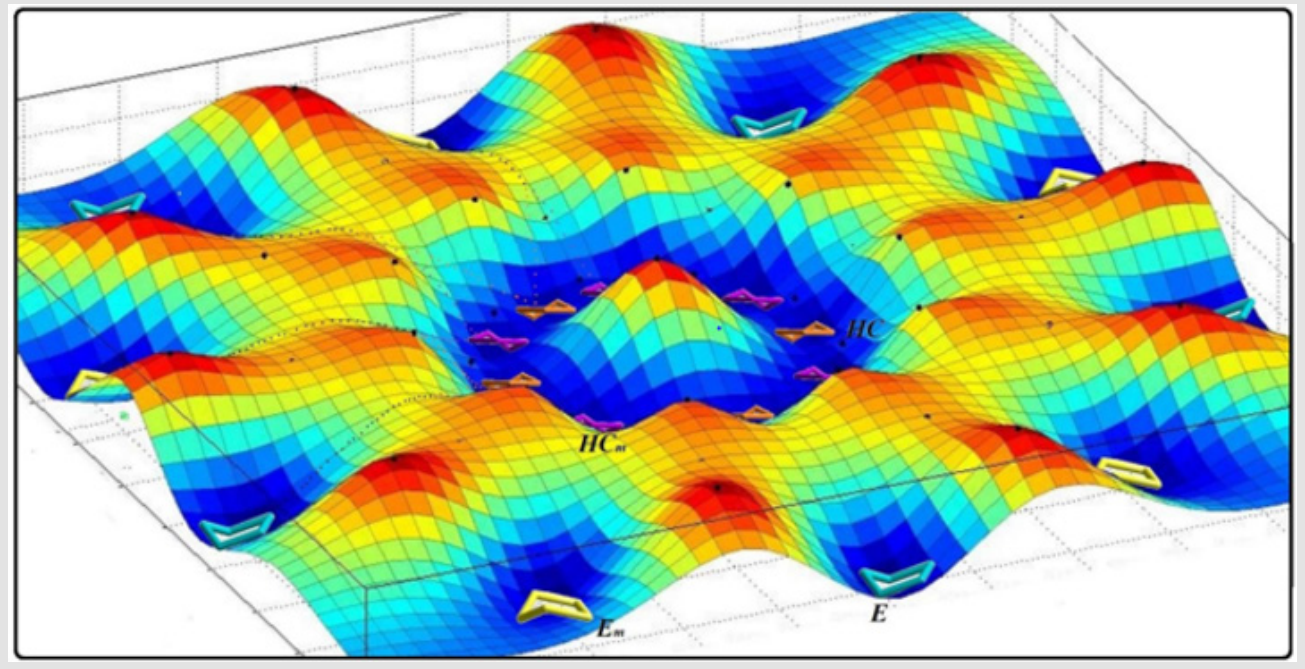

Figure 1: The conformational landscape model for cyclopentane emphasizing the role of ring coordinates to separate Bent and twist conformers.

\section{Methods}

To study conformational forms in parent Cis-Octahydropentalenes as well as Chondrosterin, most local density functional methods, slightly overestimate barriers due to their inability to account for van der Waals attractions in twist conformations $[15,16]$. However, density functional methods like xb97xd, in particular yield results similar if not close to those obtained via correlational methods like MP2. The $\omega$ b97xd (used here) can reliably result in accurate van der Waals modifications. The geometries computations were done at $\omega b 97 x d / 6-311+G(d)$ level [17-19], using Gaussian g09 package [20]. Larger basis sets like 6-311+G(d,p) proved small to no better accuracy.

\section{Results and Discussion}

In fused five membered rings like octahydropentalenes, cisoctahydropentalene is not only the most stable form but is also a partially flexible molecule. There are 13 double bent forms (cEE), 8 bent twist forms(cHCE) and 2 double twist forms (cHCCH) as well. In order to categorize and recognize better we'll look all the cis conformers in a direction that hydrogens are in the back of the plane shown. Out of plane atom in the envelope forms are shown with a dot sign if coming toward us and with cross sign if pointing away. To suggest a patterned conformational landscape the main focus was on the puckering and ring coordinate for double envelope forms (Figure 2). Energies for all of these conformers are given in (Table 1). These double bent forms not only are the most stable have the most symmetric conformer class with C2 symmetric forms. Twist conformers lie between 4.5 and $6 \mathrm{kcal} / \mathrm{mol}$ higher than the double bent while cHCHC1 is $2.5 \mathrm{kcal} / \mathrm{mol}$ higher, and the other double half-chair is about $6.8 \mathrm{kcal} / \mathrm{mol}$ higher than the reference cEE3 conformer.

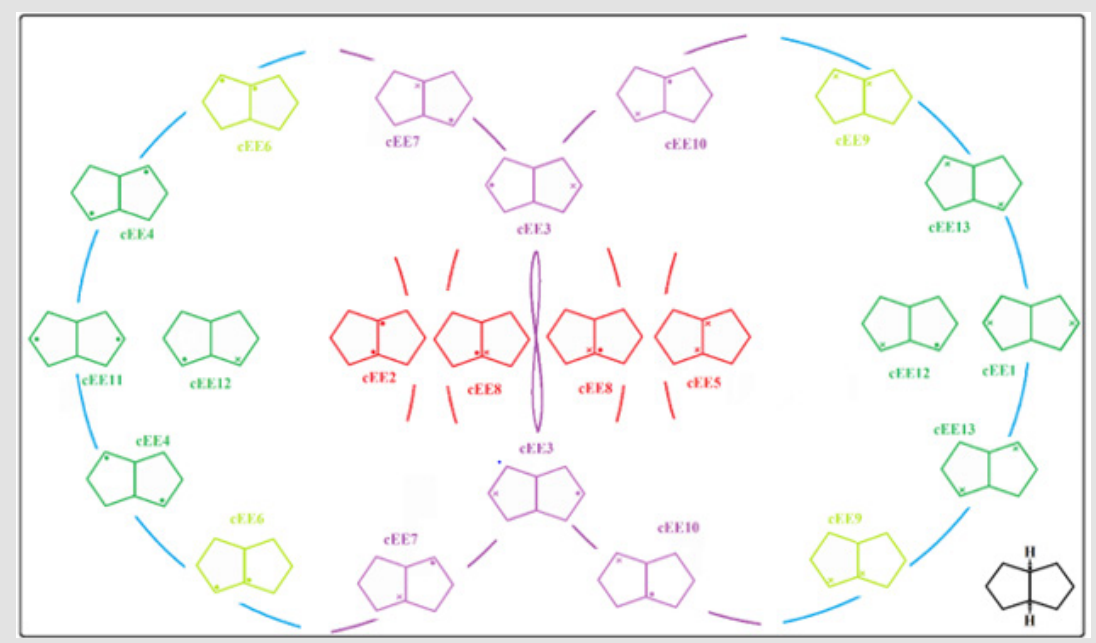

Figure 2: Conformational landscape for cis-Octaheydropentalene based of the 13 double bent conformers building parts of a pseudorotational ring coordinate. 
Table 1: Energies and symmetry point groups for Double bent Conformers of Cis-Octahydropentalene.

\begin{tabular}{|c|c|c|c|}
\hline \multicolumn{2}{|c|}{ cis-Octahydropentalene } & \multicolumn{2}{|c|}{ DFT $\omega b 97 x d / 6-311+G^{*}$} \\
\hline Conformer type & $\begin{array}{l}\text { Conformer } \\
\text { number }\end{array}$ & Symmetry & $\mathrm{E}_{\mathrm{rel}}(\mathrm{KCal} / \mathrm{mol})$ \\
\hline \multirow{13}{*}{$\begin{array}{l}\text { Double Bent } \\
\text { Conformers }\end{array}$} & cEE1 & $\mathrm{C}_{2 \mathrm{v}}$ & 1.2 \\
\hline & cEE2 & $\mathrm{C}_{2}$ & 3.9 \\
\hline & cEE3 & $\mathrm{C}_{2 \mathrm{~h}}$ & 0 \\
\hline & cEE4 & $\mathrm{C}_{2}$ & 2.1 \\
\hline & cEE5 & $\mathrm{C}_{2}$ & 3.7 \\
\hline & cEE6 & $\mathrm{C}_{1}$ & 4.2 \\
\hline & cEE7 & $\mathrm{C}_{1}$ & 3.8 \\
\hline & cEE8 & $\mathrm{C}_{1}$ & 3.9 \\
\hline & cEE9 & $\mathrm{C}_{1}$ & 4.3 \\
\hline & cEE10 & $\mathrm{C}_{1}$ & 4.2 \\
\hline & cEE11 & $\mathrm{C}_{2 \mathrm{v}}$ & 1.7 \\
\hline & cEE12 & $\mathrm{C}_{1}$ & 2.4 \\
\hline & cEE13 & $\mathrm{C}_{2}$ & 2.0 \\
\hline
\end{tabular}

The main role is played by conformer cEE9/cEE6 and cEE3, with the formers acting as a dynamic rapped bioactive part. This shows that most mobile atoms are the ones farthest from the junction carbons. The cEE2 and cEE5 are the only isolated double envelopes, which are only accessible via cEE6 and EE9 respectively. Both of which have been identified here in Chondrosterin to act as conformational trap sites. They both have their out of plane carbons as the junction carbons, which serve as a lock to any plausible ring flipping. Chondrosterin have also been reported to have major conformer cEE9 and cEE3. Populated the same major conformer a dime has also been identified via crystallographic studies (Figure 3 ). Cis-octahydropentalenes are both more stable and of more frequent occurrences in nature compared to their trans isomers. Cedrol, Meldrum's acid [21], Aburatsubo lactam, (-)-a-Cederene and (+)-b-Cedrene, all a cis-octahydropentalene skeletal substructure. Natural cedrol and Cederenes are the essential components in cedar oils of most coniferous trees [22]. Aburatsubo lactam is a novel inhibitor of superoxide anions isolated from a marine organism [11].

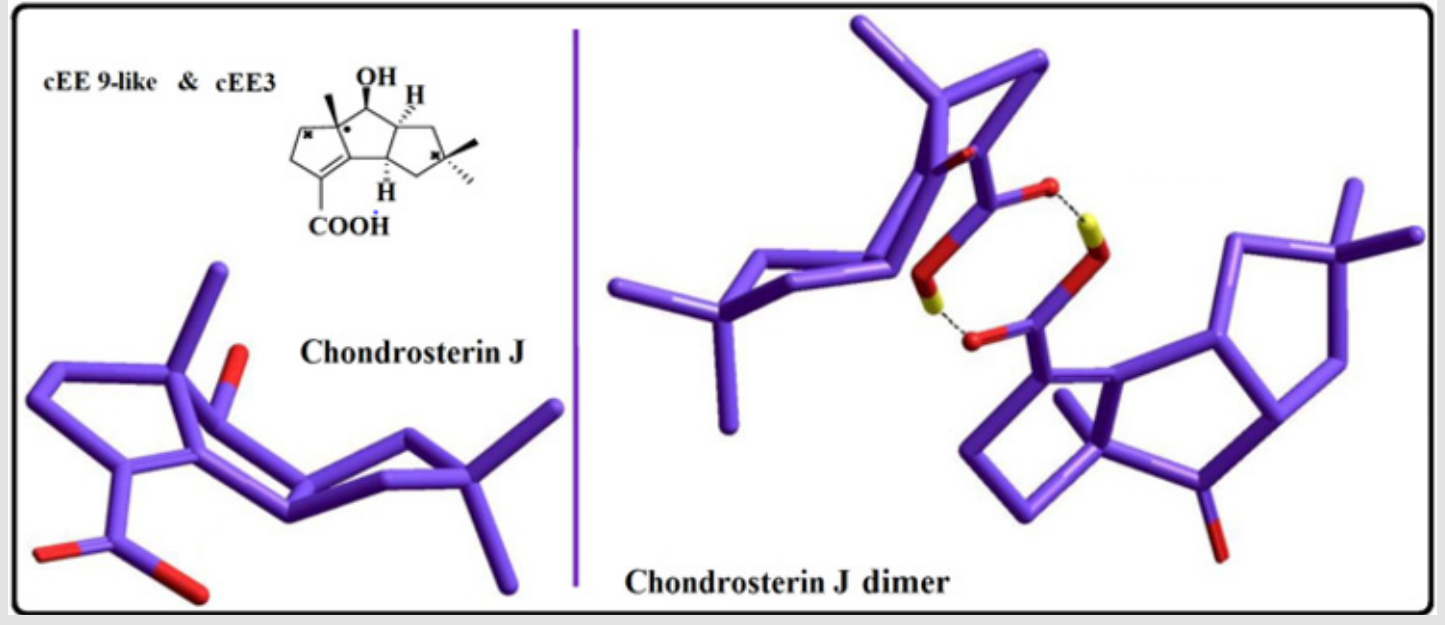

Figure 3: Conformational Preferences in marine natural product, Chondrosterin J, in the family of triquinane sesquiterpenes.

\section{Conclusion}

In conclusion, we have suggested a reasonable Conformational landscape for cis- Octaheydropentalene. The pattern successfully explains the bioactive conformation in Chondrosterin, a marine natural product with potent bioactivity. Seemingly contradictory properties of Chondrosterin's major conformer cEE9, as both a flexible and yet highly populated conformer, strongly suggests, natures choice to select cis-Octaheydropentalene frameworks in many natural products. Analysis like these are not only illustrative on how nature can use certain scaffolds to achieve bioactivity at its highest potency but would fuel biomedical research in the drug design area.

\section{References}

1. Ashwell G, Morell AG (1974) The role of surface carbohydrates in the hepatic recognition and transport of circulating glycoproteins. Advances in enzymology and related areas of molecular biology 41(0): 99-128.
2. Hoffmann RW (2000) Conformation design of open-chain compounds. Angewandte Chemie International Edition 39(12): 2054-2070.

3. Saran A, Perahia D, Pullman B (1973) Molecular orbital calculations on the conformation of nucleic acids and their constituents. Theoretica chimica acta 30: 31-44.

4. Kilpatrick JE, Pitzer KS, Spitzer R (1947) The thermodynamics and molecular structure of cyclopentane1. Journal of the American Chemical Society 69(10): 2483-2488.

5. Pitzer KS, Donath WE (1993) Conformations and strain energy of cyclopentane and its derivatives, Molecular Structure and Statistical Thermodynamics: Selected Papers of Kenneth S Pitzer. World Scientific pp. 98-103.

6. Wertz D (1969) Far-Infrared Absorption Spectrum and Pseudorotation of the Thiacyclopentane Molecule. The Journal of Chemical Physics 51: 2133-2136.

7. Allinger NL, Hirsch JA, Miller MA, Tyminski IJ, Van Catledge FA (1968) Conformational analysis. LX. Improved calculations of the structures and energies of hydrocarbons by the Westheimer method. Journal of the American Chemical Society 90(5): 1199-1210. 
8. Carreira L, Lord R (1969) Ring-Puckering Potential Functions of Some Oxygen-Containing Molecules.

9. Green W, Harvey A (1971) Greenhouse Spectroscopic Determination of the Pseudo rotation Barrier in Selenacyclopentane. The Journal of Chemical Physics 54: 850-856.

10. During J, Willis J (1970) Spectra and Structure of Small Ring Compounds. XIX. Vibrational Analysis and the Barrier to Pseudorotation of Germylcyclopentane. The Journal of Chemical Physics 52: 6108-6119.

11. Marino J (1988) New strategies for annulations: a highly convergent and stereoselective synthesis of an octahydronaphthalene synthon for dihydrocompactin. Journal of the American Chemical Society 110(23): 7916-7917.

12. Laane J (1969) Far-Infrared Spectrum and the Barrier to Pseudorotation of Silacyclopentane. The Journal of Chemical Physics 50: 1946-1951.

13. Kowalewski P, Frey HM, Infanger D, Leutwyler S (2015) Probing the structure, pseudorotation, and radial vibrations of cyclopentane by femtosecond rotational Raman coherence spectroscopy. The Journal of Physical Chemistry A 119(45): 11215-11225.

14. Brügger G, Frey HM, Steinegger P, Balmer F, Leutwyler S (2011) Accurate determination of the structure of cyclohexane by femtosecond rotational coherence spectroscopy and ab initio calculations. The Journal of Physical Chemistry A 115: 9567-9578.

\section{ISSN: 2574-1241}

DOI: 10.26717/BJSTR.2019.22.003708

Nader Sakhaee. Biomed J Sci \& Tech Res

This work is licensed under Creative Commons Attribution 4.0 License

Submission Link: https://biomedres.us/submit-manuscript.php
15. Halgren TA (1996) Merck molecular force field. II. MMFF94 van der Waals and electrostatic parameters for intermolecular interactions, Journal of Computational Chemistry 17: 520-552.

16. Giesen DJ, Gu MJ, Cramer CJ, Truhlar DG (1996) A universal organic solvation model. The Journal of organic chemistry 61(25): 8720-8721.

17. Shao Y, Molnar LF, Jung Y, J Kussmann, Ochsenfeld C (2006) Advances in methods and algorithms in a modern quantum chemistry program package. Physical Chemistry Chemical Physics 8: 3172-3191.

18. Frisch M, Trucks G, Schlegel HB, Scuseria GE, Robb MA, et al. Gaussian 09, revision a. 02, gaussian, Inc, Wallingford, CT, UK, pp. 200.

19. Frisch M, Trucks G, Schlegel HB, Scuseria GE, Robb MA, et al. (2009) JR Cheeseman, G Scalmani, V Barone, B Mennucci, G Petersson (Eds.) Gaussian 09, revision D 01, Gaussian, Inc, Wallingford, CT, UK.

20. Hratchian HP, Parandekar PV, Raghavachari K, Frisch T, Vreven (2008) QM: QM electronic embedding using Mulliken atomic charges: Energies and analytic gradients in an ONIOM framework. The Journal of chemical physics 128(3): 034107.

21. Sautier B, Lyons SE, Webb MR, Procter DR (2011) Radical cyclization cascades of unsaturated meldrum's acid derivatives. Organic letters 14(12): 146-149.

22. Singh A, Upadhye A, Wadia A, Mhaskar V, Dev S (1969) Chemistry of lac resin-II lac acids (Part 2): Laccijalaric acid. Tetrahedron 25: 3855-3867.

$\begin{array}{ll}\text { BIOMEDICAL } & \text { Assets of Publishing with us } \\ \text { RESEARCHES } & \text { - Global archiving of articles } \\ & \text { - Immediate, unrestricted online access } \\ & \text { - Rigorous Peer Review Process } \\ \end{array}$

